\title{
Adiponectin as a Potential Marker of Prostate Cancer Progression: Studies in Organ-Confined and Locally Advanced Prostate Cancer
}

\author{
D. HOUSA, Z. VERNEROVÁ, J. HERÁČEK ${ }^{1}$, B. PROCHÁZKA ${ }^{2}$, P. ČECHÁK ${ }^{3}$, \\ J. KUNCOVÁ ${ }^{1}$, M. HALUZÍK ${ }^{4}$
}

Department of Pathology, and ${ }^{1}$ Department of Urology, Third Medical Faculty and Teaching Hospital Královské Vinohrady, Prague, ${ }^{2}$ Department of Biostatistics and Informatics, National Institute of Public Health, Prague, ${ }^{3}$ Department of Biochemistry and Pathobiochemistry, Third Medical Faculty and Teaching Hospital Kralovske Vinohrady, ${ }^{4}$ Third Department of Internal Medicine, First Faculty of Medicine and General Faculty Hospital, Prague, Czech Republic

Received November 13, 2006

Accepted February 19, 2007

On-line April 25, 2007

\section{Summary}

Serum levels of adiponectin were measured in patients with benign prostatic hyperplasia and prostate cancer of pT2 and pT3 stage. Adiponectin ELISA assay, immunohistochemistry, and selected metabolic and biochemical parameters measurement was performed in 25 patients with benign prostatic hyperplasia and 43 with prostate cancer (17 patients with organ-confined and 26 patients with locally advanced disease). Serum adiponectin levels did not differ between prostate benign hyperplasia and cancer clinical stage T2, but was significantly higher in PT3 relative to $\mathrm{pT} 2$ group $(14.51 \pm 4.92$ vs. $21.41 \pm 8.12, \mathrm{P}=0.003)$. Tissue immunohistochemistry showed enhanced staining in neoplastic prostate glands and intraepithelial neoplasia relative to benign prostatic hyperplasia without distinction between disease grade and stage. Serum adiponectin levels are higher in locally advanced relative to organ-confined prostate cancer and may thus serve as an auxiliary marker providing further improvement for discrimination between pT2 and pT3 stages.

\section{Key words}

Prostate cancer • Adiponectin • Immunohistochemistry

\section{Corresponding author}

Martin Haluzík, Third Department of Internal Medicine, First Faculty of Medicine and General Faculty Hospital Prague, U nemocnice 2, 12800 Prague 2, Czech Republic. E-mail: Martin.Haluzik@lf1.cuni.cz

\section{Introduction}

Prostate cancer $(\mathrm{PCa})$, the third most common cancer in men worldwide, represents an important health and socio-economical problem in Western countries with increasing prevalence due to higher proportion of elderly population. Besides populational influence, the development of better methods for early detection of prostate cancer led to the substantial increase in number of cases. Except proposed genetic factors like higher circulating sex steroid levels, shorter androgen receptor CAG (glutamine) repeat length, genetic variability of steroid 5 $\alpha$-reductase enzyme gene and polymorphic variation in the VDBP (vitamin D-binding protein) gene, environmental factors may also contribute to the process of conversion of latent or histological/microscopic cancer to the clinically overt one. The most commonly studied environmental factors in connection with prostate cancer are diet with higher content of saturated fat and obesity itself: both being very common as a result of Western lifestyle with abundance of food (Gann 2002). Fat consumption correlates well with the prostate cancer mortality rate in most studies around the world (Le Marchand et al. 1994), although this finding was not confirmed by all studies (Andersson et al. 1995). This observation might reflect the fact that high levels of dietary fat stimulate proliferation of prostate cancer cells (Aronson et al. 1999). Obesity itself is a general risk factor for the development of some forms of cancer 
including the prostate, breast, endometrial and colon cancer (Calle and Thun 2004). However, it should be noted that the studies focused on the relationship between obesity and prostate cancer did not yield completely consistent results. While several studies found an increased risk of prostate cancer among obese and overweight men (Andersson et al. 1997), others revealed little or no association (Giovannucci et al. 1997). According to the results of some studies, body mass index and in particular visceral obesity correlates with the aggressiveness and mortality of prostate cancer (Hsing et al. 2002). In patients with established diagnosis of prostate cancer, obesity is a predictor of poor prognosis and is associated with higher tumor stage and grade (Freedland et al. 2004). The convincing evidence for the role of diet in modulation of prostate cancerogenesis came from migration studies showing an increased incidence of prostate cancer in first-generation immigrants to US from Japan and China linking increased incidence of prostate cancer to the change of diet higher in saturated fat (Shimizu et al. 1991).

A discovery of endocrine function of adipose tissue opened another possible link between obesity and cancerogenesis. Adipose tissue is the source of numerous circulating hormones that may participate in the development and progression of different forms of malignant tumors (Housa et al. 2006) including prostate cancer (Freedland et al. 2005, Somasundar et al. 2004). Adiponectin is an adipose tissue-derived hormone expressed almost exclusively in adipocytes with significant anti-diabetic, anti-atherosclerotic and antiinflammatory properties as demonstrated by experimental rodent studies (Kadowaki and Yamauchi 2005). There are several lines of evidence suggesting that adiponectin may play a substantial role in cancer pathogenesis. Circulating levels of adiponectin were inversely associated with the risk of breast, endometrial, colon and gastric cancer in several studies (Dal Maso et al. 2004, Ishikawa et al. 2005, Mantzoros et al. 2004, Miyoshi et al. 2003, Petridou et al. 2003, Wei et al. 2005). Furthermore, in vitro data suggest that adiponectin inhibits cell proliferation, induces apoptosis and suppresses tumor growth due to its antiangiogenic properties exerting its effect via downstream common effectors c-Jun $\mathrm{NH}_{2}$ terminal kinase (JNK) and signal transducer and activator of transcription 3 (STAT3) (Miyazaki et al. 2005). Recent studies showed that non-proteolytic full-length adiponectin inhibited the growth of androgen-dependent and androgen-independent prostate cancer cell lines thus serving as a link between obesity and prostate cancer (Bub et al. 2006). An inverse association between serum adiponectin levels and histological grade, disease stage as well as aggressiveness of prostate cancer was reported by Freedland et al. 2004, 2005a,b, Goktas et al. 2005), but these results were not confirmed in the recent study of Baillargeon et al. (2006).

In this study, we evaluated serum levels and tissue expression of adiponectin in well-characterized patients undergoing simple suprapubic prostatectomy for BPH (benign prostatic hyperplasia) and radical retropubic prostatectomy for organ-confined (pT2) or locally advanced prostate cancer (pT3) preoperatively clinically staged as T2 disease and we studied the relationship of adiponectin levels with tumor stage, grade and selected hormonal, metabolic and biochemical parameters.

\section{Methods}

\section{Study subjects}

Sixty-eight men referred to undergo either simple prostatectomy for benign prostatic hyperplasia or radical prostatectomy for prostate cancer preoperatively diagnosed with clinical stage T2 from December 2004 to May 2005 at the Department of Urology, Teaching Hospital Kralovske Vinohrady were enrolled into the study. Of those, 25 patients had benign prostatic hyperplasia and 43 patients had prostate cancer of clinical stage T2. None of patients had prior radiotherapy, chemotherapy, hormonal treatment including androgen deprivation therapy or suffered from an acute illness. The prostate cancer patients were stratified for further evaluation into two groups based on the disease extension: 17 patients with organ-confined (pT2 pathological stage) and 26 patients with locally advanced disease (pT3 pathological stage). The patients in pT2 group were followed up for 16-20 months and none of the subjects reported local recurrence or metastatic disease development. The study protocol was approved by the local ethical committee. All participating subjects were informed about the purpose of the study and provided written informed consent.

\section{Anthropometric examination and blood sampling}

Patients underwent a single physical examination, were measured and weighed and BMI (body mass index) was calculated as the weight in kilograms divided by the height in square meters. Peripheral venous blood samples were collected after an overnight fast at 
the morning of the day of surgery between 6:00 and 8:00 and centrifuged for $20 \mathrm{~min}$ at $2000 \mathrm{rpm}$. The serum was separated, aliquoted and kept frozen at $-80^{\circ} \mathrm{C}$ until further analysis.

\section{Hormonal and biochemical assays}

Serum adiponectin levels were measured using commercial RIA kit (Linco Research, St. Charles, Missouri, USA). Sensitivity was $1.0 \mathrm{ng} / \mathrm{ml}$, and the intraand interassay variability were $1.78 \%$ and $8.25 \%$, respectively. Serum total prostate specific antigen (PSA) and free PSA levels, cortisol, prolactin, testosterone, SHBG, FAI, DHEAS, estradiol, progesterone, LH, FSH, insulin, fasting plasma glucose, triglycerides, highdensity lipoprotein cholesterol, low-density lipoprotein cholesterol and total cholesterol were measured at the Department of Biochemistry, Teaching Hospital Kralovske Vinohrady, Prague, by standard laboratory methods.

\section{Prostatectomy specimens processing}

Each radical or simple prostatectomy whole specimen was fixed in $4 \%$ buffered formaldehyde, totally embedded and processed as complete sampling with routine sections described previously (True 1994). All specimens were examined at the Department of Pathology, Teaching Hospital Kralovske Vinohrady, Prague, graded according to the Gleason grading scheme and pathological staging based on UIAC TNM Classification of Malignant Tumours, Sixth edition was performed. Total prostate volume was calculated using the ellipsoidal method $(4 / 3 \times \pi \times$ (length $/ 2 \times$ width $/ 2 \times$ height/2)) and prostate cancer volume was calculated based on the thickness of tissue sections and measurement of area occupied by tumor by analySIS 3.2 image analysis software (Soft Imaging Systems $\mathrm{GmbH}$, Münster, Germany).

\section{Immunohistochemistry}

Immunohistochemistry was performed in a subset of patients ( $\mathrm{n}=10$ from each group) covering both low and high serum levels of adiponectin of all three studied groups (BPH, pT2 and pT3). Five-micron-thick sections cut from formalin-fixed, paraffin-embedded tissue samples were deparaffinized in xylene and rehydrated. Endogenous peroxidase activity was inhibited by $3 \% \mathrm{H}_{2} \mathrm{O}_{2}$ in methanol for $30 \mathrm{~min}$ followed by $15 \mathrm{~min}$ rinsing in tap water. Non-specific reactivity was avoided by pretreatment sections with $1 \%$ normal goat serum (Dako Cytomation, Glostrup, Denmark) with $1 \%$ bovine fetal albumin for $2 \mathrm{~h}$. The slides were incubated with polyclonal rabbit anti-adiponectin antibody Arcp30 (N-20) (Santa Cruz Biotechnology, Inc., California, USA), diluted to 1:250 with ChemMate Antibody Diluent (Dako Cytomation, Glostrup, Denmark). The Histofine ${ }^{\circledR}$ kit (Nichirei, Tokyo, Japan) was used to visualize sections incubated with primary antibody. The chromogen 3,3-diaminobenzidine (Liquid DAB+ Substrate, Dako Cytomation, Glostrup, Denmark) was applied to all sections and counterstaining was performed with Mayer's hematoxylin. Tissue sections incubated without primary antibody and with normal rabbit immunoglobulin fraction (Dako Cytomation, Glostrup, Denmark) were used as negative controls.

All sections were analyzed using Nikon Eclipse E600 microscope in a random order by two pathologists who were unaware of clinical data. The intensity of adiponectin expression was scored on a four-point scale $(0-3)$. In terms of the staining intensity, 0 represented lack of positivity, while a score of 1 to 3 represented weak, moderate, and strong immunohistochemical positivity, respectively. In a case of borderline staining intensity the difference between observers was solved by a secondary evaluation.

Table 1. Anthropometric and biochemical parameters in patients with benign prostatic hyperplasia and prostate cancer.

\begin{tabular}{lccc}
\hline & Benign prostatic hyperplasia $(\mathbf{n = 2 5})$ & Prostate cancer $(\mathbf{n = 4 3})$ & P \\
\hline Age (years) & $70.52 \pm 8.73$ & $63.61 \pm 4.71$ & $<0.001^{* * *}$ \\
BMI $\left(\mathrm{kg} / \mathrm{m}^{2}\right)$ & $27.55 \pm 3.36$ & $27.43 \pm 3.10$ & 0.88 \\
Serum adiponectin $(\mathrm{ng} / \mathrm{ml})$ & $20.47 \pm 10.13$ & $18.68 \pm 7.75$ & 0.64 \\
Total PSA $(\mathrm{ng} / \mathrm{ml})$ & $8.02 \pm 6.83$ & $9.49 \pm 8.66$ & 0.18 \\
Free PSA $(\mathrm{ng} / \mathrm{ml})$ & $1.37 \pm 2.07$ & $0.91 \pm 0.80$ & 0.22 \\
F/T PSA $(\mathrm{ng} / \mathrm{ml})$ & $0.22 \pm 0.20$ & $0.10 \pm 0.057$ & $<0.001^{* * *}$ \\
\hline
\end{tabular}


Table 2. Anthropometric, clinico-pathological, metabolic and biochemical parameters in patients with organ-confined and advanced prostate cancer group.

\begin{tabular}{|c|c|c|c|}
\hline & $\begin{array}{l}\text { Organ confined prostate cancer } \\
\qquad(n=17)\end{array}$ & $\begin{array}{l}\text { Advanced prostate cancer } \\
\qquad(\mathrm{n}=\mathbf{2 6})\end{array}$ & $\mathbf{P}$ \\
\hline Age (year) & $62.71 \pm 5.22$ & $64.19 \pm 4.35$ & 0.31 \\
\hline$B M I\left(\mathrm{~kg} / \mathrm{m}^{2}\right)$ & $27.22 \pm 3.24$ & $27.56 \pm 3.06$ & 0.73 \\
\hline Normal (less than 25) & 4 & 5 & \\
\hline Overweight (25-less than 30) & 10 & 16 & \\
\hline Obese (30 or greater) & 3 & 5 & \\
\hline Prostate volume $\left(\mathrm{cm}^{3}\right)$ & $35.66 \pm 16.33$ & $28.71 \pm 14.21$ & 0.15 \\
\hline Total cancer volume $\left(\mathrm{cm}^{3}\right)$ & $12.64 \pm 10.31$ & $14.58 \pm 7.00$ & 0.49 \\
\hline Serum adiponectin $(\mathrm{ng} / \mathrm{ml})$ & $14.51 \pm 4.92$ & $21.41 \pm 8.12$ & $0.003 * *$ \\
\hline Total PSA $(\mu g / l)$ & $6.30 \pm 2.22$ & $11.58 \pm 10.55$ & $0.024 *$ \\
\hline Free PSA $(\mu g / l)$ & $0.72 \pm 0.46$ & $1.04 \pm 0.95$ & 0.42 \\
\hline$F A I(\%)$ & $47.37 \pm 16.52$ & $44.12 \pm 16.50$ & 0.58 \\
\hline$F / T P S A$ & $0.11 \pm 0.06$ & $0.10 \pm 0.05$ & 0.63 \\
\hline Testosterone (nmol/l) & $13.04 \pm 6.16$ & $15.66 \pm 10.13$ & 0.52 \\
\hline$L H(U / l)$ & $3.66 \pm 1.88$ & $4.08 \pm 4.28$ & 0.57 \\
\hline FSH $(U / l)$ & $5.70 \pm 2.56$ & $7.74 \pm 8.09$ & 0.70 \\
\hline Cortisol (nmol/l) & $506.00 \pm 191.24$ & $476.69 \pm 167.39$ & 0.61 \\
\hline Prolactin $(\mu g / l)$ & $23.87 \pm 19.17$ & $14.93 \pm 13.11$ & 0.08 \\
\hline Progesterone (nmol/l) & $5.89 \pm 5.00$ & $4.24 \pm 1.62$ & 0.40 \\
\hline Estradiol $(\mathrm{pmol} / \mathrm{l})$ & $76.83 \pm 22.35$ & $82.91 \pm 43.71$ & 0.81 \\
\hline DHEAS ( $\mu \mathrm{mol} / \mathrm{l})$ & $35.59 \pm 67.53$ & $45.80 \pm 64.52$ & 0.10 \\
\hline SHBG $(\mathrm{nmol} / \mathrm{l})$ & $38.54 \pm 23.79$ & $34.99 \pm 14.90$ & 0.99 \\
\hline$C R P(m g / l)$ & $5.26 \pm 6.07$ & $5.58 \pm 6.49$ & 0.83 \\
\hline Glucose (mmol/l) & $5.66 \pm 2.31$ & $5.08 \pm 1.42$ & 0.24 \\
\hline Insulin $(m U I / l)$ & $5.46 \pm 4.16$ & $4.73 \pm 4.18$ & 0.33 \\
\hline Cholesterol (mmol/l) & $4.76 \pm 0.95$ & $5.26 \pm 0.84$ & 0.08 \\
\hline LDL $(\mathrm{mmol} / \mathrm{l})$ & $2.94 \pm 0.77$ & $3.21 \pm 0.60$ & 0.21 \\
\hline$H D L(\mathrm{mmol} / \mathrm{l})$ & $1.14 \pm 0.23$ & $1.28 \pm 0.21$ & 0.08 \\
\hline Triglycerides (mmol/l) & $1.63 \pm 0.65$ & $1.72 \pm 0.84$ & 0.71 \\
\hline Gleason sum score 2-4 & 3 & 0 & \\
\hline Gleason sum score 5-6 & 11 & 13 & \\
\hline Gleason sum score $3+4=7$ & 2 & 4 & \\
\hline Gleason sum score $4+3=7$ & 1 & 2 & \\
\hline Gleason sum score 8-10 & 0 & 7 & \\
\hline
\end{tabular}

Data presented as mean $\pm \mathrm{SD}, * \mathrm{P}<0.05, * * \mathrm{P}<0.01$, CRP - C-reactive protein, DHEAS - dehydroepiandrosterone sulphate, FAI free androgen index, PSA - prostate specific antigen, F/T PSA - free/total PSA, HDL - high-density cholesterol, LDL - low-density cholesterol, LH - luteinizing hormone, SHBG sex - hormone binding globulin.

\section{Statistical analysis}

The results are reported as mean \pm S.D. MannWhitney Rank Sum test and Kruskal-Wallis test with Dunnet's Method were used for comparison of the groups as appropriate. The relationships between the variables were analyzed by Spearman's correlation coefficient $\rho$.
ROC curve for serum adiponectin and PSA levels in organ-confined and locally advanced cancer was calculated (Eng 2006). Differences and correlations were considered significant at $\mathrm{p}<0.05$ and where applicable, $\mathrm{p}<0.01$ and $\mathrm{p}<0.001$ were shown.

The statistical analysis was performed with 


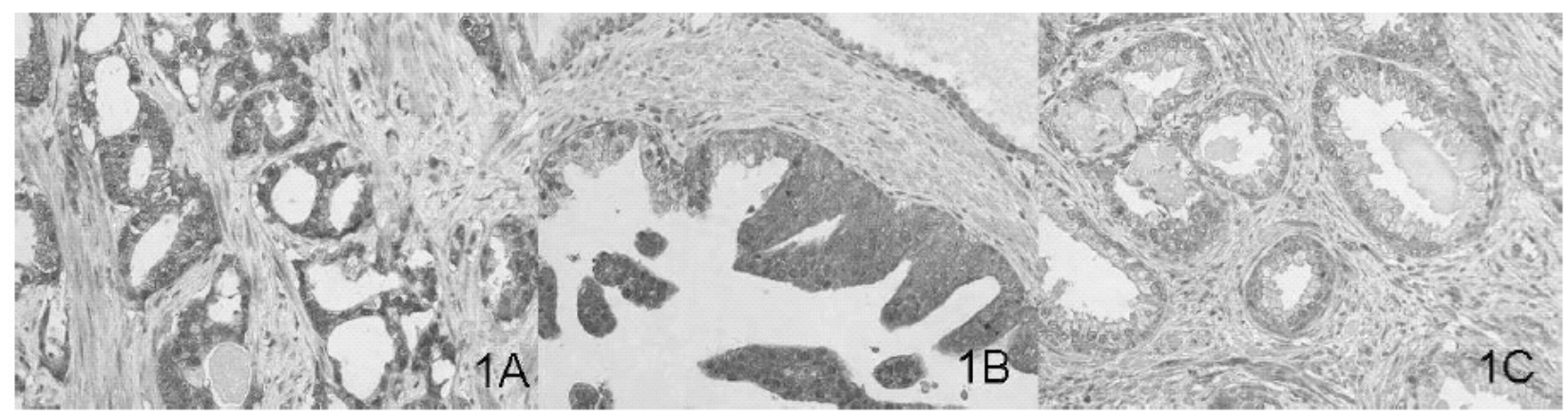

Fig 1. A. Immunohistochemical analysis of adiponectin within prostate adenocarcinoma. B. Immunohistochemical analysis of adiponectin within prostate intraepithelial neoplasia (PIN) and adjacent benign prostate gland. C. Immunohistochemical analysis of adiponectin within benign prostatic hyperplasia. Original magnification x 200

SigmaStat (Jandel Scientific, USA) and SPSS 13.0 (SPSS Inc., Chicago, IL).

\section{Results}

Baseline characteristics of all studied groups are shown in Tables 1 and 2. Most of prostate cancer patients in our study were overweight, had locally advanced disease and Gleason sum score 5 to 6 . Patients with BPH and PCa did not differ significantly with respect to serum adiponectin levels $(20.47 \pm 10.13$ vs. $18.68 \pm 7.75, \mathrm{P}=0.64$, AUC (area under the curve) $\mathrm{BPH}$ vs. $\mathrm{PCa}=0.52$ ). There was also no difference between the latter and former group in terms of BMI, total and free PSA, but there was a significant difference in F/T PSA ratio ( $0.22 \pm 0.20$ vs. $0.10 \pm 0.06$, $\mathrm{P}<0.001$ ).

When the patients were subdivided into subgroups with prostate cancer of pT2 and pT3 stage, respectively, a significantly higher adiponectin levels in locally advanced relative to organ-confined cancer were found $(14.51 \pm 4.92$ vs. $21.41 \pm 8.12, \mathrm{P}<0.005)$. Except serum adiponectin levels, significant differences were also observed between both groups in total PSA levels. It is of notion here that similar significant results were obtained after BMI adjustment of serum adiponectin levels in three studied groups (BPH vs. T2 vs. T3, $0.78 \pm 0.46$ vs. $0.56 \pm 0.26$ vs. $0.80 \pm 0.34$, for $\mathrm{T} 2$ vs. $\mathrm{T} 3$ $\mathrm{P}<0.02$, otherwise statistically non-significant).

No significant differences between $\mathrm{T} 2$ and $\mathrm{T} 3$ subgroups were found with respect to BMI, fasting plasma glucose and insulin serum levels. Similarly, we did not observe any difference between low-grade (pathological Gleason sum up to 6) and high-grade disease (pathological Gleason sum 7 or greater) with respect to adiponectin serum levels $(19.60 \pm 8.83$ vs. $17.13 \pm 5.38, \mathrm{P}=0.32)$. On the contrary, difference in
BMI between low- and high-grade disease was found ( $26.61 \pm 2.64$ vs. $28.80 \pm 3.40, \mathrm{P}<0.02$ ). After stratification into pT2a, pT2b, pT2c, pT3a and pT3b, adiponectin positively correlated with the substage of disease $(\rho=0.35, P<0.02)$ and similarly correlated PSA levels ( $\rho=0.40, P<0.01)$, but both serum markers did not correlate with each other $(\rho=0.18, P=0.24)$

The area under the ROC (receiver operating characteristics) for serum adiponectin levels in prostate cancer was calculated as 0.77 (standard error 0.07) and the optimal cut-off detecting extension of prostate cancer beyond the capsule was set at adiponectin serum level $18.2 \mathrm{ng} / \mathrm{ml}$ with sensitivity 82.4 and specificity 69.2 . When adiponectin was adjusted for BMI, area under ROC was calculated as 0.72 (standard error 0.08) and for PSA as 0.71 (standard error 0.08 ).

In organ-confined cancer a $\mathrm{P}$ trend towards inverse relationship between adiponectin levels and BMI $(\rho=-0.44, \quad P=0.07)$ was found. Furthermore, adiponectin levels positively correlated with prolactin concentrations $(\rho=0.49, P=0.05)$ while an inverse association of adiponectin was observed with total testosterone ( $\rho=-0.63, P=0.009)$, DHEAS $(\rho=-0.59$, $\mathrm{P}=0.02)$ and SHBG $(\rho=0.68, P=0.004)$. In extraprostatic extension of cancer, a trend towards an inverse association between adiponectin and BMI was observed $(\rho=-0.38, P=0.05)$ and similarly to organconfined cancer a positive correlation with prolactin $(\rho=0.43, P=0.03)$. There was also a negative correlation with insulin $(\rho=-0.40, \mathrm{P}=0.05)$.

Tissue immunostaining with adiponectin antibody showed cytoplasmic positivity both in benign and malignant prostatic glands and in some stromal elements (i.e. smooth muscle cells). Cancerous glands (Fig. 1A) and glands with prostatic intraepithelial neoplasia (Fig. 1B) showed higher staining intensity in 
comparison with adjacent benign prostatic glands (Fig. 1C). Comparable staining intensity in normal and tumor samples was observed in basal cells, basal cell hyperplasia and urothelial and squamous metaplasia. There was no obvious association between staining intensity and histological grade and stage of tumor (data not shown)

\section{Discussion}

Obesity, the excess of adipose tissue, is a wellestablished risk factor for the development of several types of malignancies. Adipose tissue produces several hormonally active substances that can participate in the process of cancerogenesis by stimulating growth, migration and invasion of tumor cells both in vitro and in vivo. Adiponectin is an adipose tissue-derived polypeptide hormone that in addition to its anti-diabetic and anti-atherogenic effects also exerts anti-angiogenic properties (Brakenhielm et al. 2004). Previous studies showed that increased serum adiponectin levels were inversely correlated with a risk of endometrial (Dal Maso et al. 2004, Petridou et al. 2003), breast (Mantzoros et al. 2004, Miyoshi et al. 2003), colon (Wei et al. 2005) and gastric cancer (Ishikawa et al. 2005).

The relationship between serum adiponectin levels and prostate cancer was evaluated in three recently published studies. Goktas et al. (2005) found lower adiponectin levels in poorly differentiated and extraprostatic prostate cancer than in well- or moderately differentiated prostate cancer and organ-confined disease. In addition, a negative association between histological grade and stage of prostate cancer and plasma adiponectin levels was observed. Similarly, Freedland et al. (2005) found an inverse relationship between adiponectin and BMI as well as inverse association of adiponectin with high-grade disease in overweight and obese man. In normal weight and in overweight and obese men with high-grade disease adiponectin was positively associated with high stage disease. On the contrary, Baillargeon et al. et al. (2006) found that adiponectin did not correlate with prostate cancer aggressiveness or cancer risk. In our study, we observed no significant difference in adiponectin levels between benign prostatic hyperplasia and prostate cancer and between low-grade and high-grade disease, but we found significantly higher adiponectin concentrations in patients with locally advanced disease stage relative to organconfined cancer.
There are several possible explanations for different findings with respect to serum adiponectin levels between our and other studies cited above. Firstly, in the study of Goktas et al. (2005) the patients were stratified into the groups based on the results of transrectal ultrasound-guided biopsy and the same approach was used for grading of disease. This approach could be less precise than diagnosis of tumor stage and grade based on the histological examination of samples obtained by retropubic radical prostatectomy specimens in prostate cancer as used in our study. Furthermore, the population in the previous study had mostly normal weight, while in our study most of the subjects were overweight. Our data are to some extent similar to the results of Freedland et al. (2005) who did not find any association between plasma adiponectin and grade before adjusting the patients' subgroups with logistic regression and to the results of Baillargeon et al. (2006) who did not find any difference in serum adiponectin concentrations between control and prostate cancer and between high grade and low-grade disease.

As described above, we found significantly higher adiponectin levels in extended relative to organconfined prostate cancer and positive correlation with prostate cancer substaging as well. The addition of serum adiponectin to PSA levels provided further improvement to prostate cancer staging. Based on these finding we suggest that adiponectin levels may provide a novel auxiliary marker for discrimination between organconfined and locally advanced prostate cancer.

Our data suggested the link between adiponectin levels and prostate cancer progression. The opened question remains whether this is a causal relationship or whether the changes of adiponectin levels are rather the consequence of some metabolic changes present in more progressive but not organ-confined cancer. Here we found no significant differences in anthropometric and metabolic parameters such as BMI, blood glucose and serum insulin levels when comparing patients with advanced vs. organ-confined diseases. These findings support the idea that the difference in adiponectin levels is not a secondary result of metabolic changes. One attractive although rather speculative possibility is that increased serum adiponectin levels may serve as a protective factor against further tumor progression. It has been previously demonstrated that adiponectin has in general antiproliferative effects either through direct mechanism or by activating AMP activated protein kinase. As adiponectin did not correlate with PSA levels 
in our study we may speculate that both serum markers work through different pathways and possibly reflect different places of production. In support of this hypothesis, we were unable to demonstrate immunohistochemically the adiponectin immunoreactivity in DU145 prostate cancer cell line growing in the absence of surrounding stroma and/or fat tissue, whereas we found an enhanced adiponectin immunostaining in the epithelium of malignant glands and PIN (prostate intraepithelial neoplasia) in the whole tissue sections recruited from prostate specimens (data not shown). Similarly to our results, recently it was shown that adiponectin receptors are expressed at mRNA and protein levels in prostate cancer cell lines while mRNA for adiponectin was undetectable (Mistry et al. 2006). Therefore it is possible that adiponectin released from periprostatic fat after breach of capsule or from interstitial stromal tissue surrounding epithelium of prostate glands binds increasingly to its receptors in (pre)malignant epithelium and after its selective uptake acts on it in an autocrine/paracrine fashion.

Increased serum adiponectin levels in patients with advanced disease stage (pT3) observed in our study differ from previously published results in patients with other malignancies (breast, gastric, colon and endometrial cancer) where inverse association of adiponectin levels and tumor stage was observed. However, it should be stressed that advanced stage of breast, colon and endometrial cancer is often linked to cachexia with the deliberation of cytokines, including TNF- $\alpha$, lowering serum adiponectin levels. Higher cancer stage in colon and endometrial cancer is also linked with serosal surface perforation with the extension of cancerous cells in the peritoneal cavity with possible direct modulation of adiponectin production.

In conclusion, in our study on a limited number of patients we showed that serum adiponectin levels did not differ between patients with benign hyperplasia and prostate cancer of clinical stage T2. However, adiponectin levels were significantly higher in pT3 relative to pT2 stage prostate cancer patients. We suggest that circulating adiponectin levels may serve as an auxiliary marker for discrimination of organ-confined and locally advanced prostate cancer stage.

\section{Conflict of Interest}

There is no conflict of interest.

\section{Acknowledgements}

The authors thank Dr. Vaclav Eis for helpful discussion and Renáta Hájková and Andrea Musilová for technical assistance. This work was supported by Internal Grant Agency of Ministry of Health of the Czech Republic NRI 8096-3 to J. Heráček and Project Oncology Nr. MSM0021620808 by the Ministry of Education of The Czech Republic to Z. Vernerová.

\section{References}

ANDERSSON SO, BARON J, WOLK A, LINDGREN C, BERGSTROM R, ADAMI HO: Early life risk factors for prostate cancer: a population-based case-control study in Sweden. Cancer Epidemiol Biomarkers Prev 4: $187-$ $192,1995$.

ANDERSSON SO, WOLK A, BERGSTROM R, ADAMI HO, ENGHOLM G, ENGLUND A, NYREN O: Body size and prostate cancer: a 20-year follow-up study among 135006 Swedish construction workers. J Natl Cancer Inst 89: 385-389, 1997.

ARONSON WJ, TYMCHUK CN, ELASHOFF RM, MCBRIDE WH, MCLEAN C, WANG H, HEBER D: Decreased growth of human prostate LNCaP tumors in SCID mice fed a low-fat, soy protein diet with isoflavones. Nutr Cancer 35: 130-136, 1999.

BAILLARGEON J, PLATZ EA, ROSE DP, POLLOCK BH, ANKERST DP, HAFFNER S, HIGGINS B, LOKSHIN A, TROYER D, HERNANDEZ J, LYNCH S, LEACH RJ, THOMPSON IM: Obesity, adipokines, and prostate cancer in a prospective population-based study. Cancer Epidemiol Biomarkers Prev 15: 1331-1335, 2006.

BRAKENHIELM E, VEITONMAKI N, CAO R, KIHARA S, MATSUZAWA Y, ZHIVOTOVSKY B, FUNAHASHI

T, CAO Y: Adiponectin-induced antiangiogenesis and antitumor activity involve caspase-mediated endothelial cell apoptosis. Proc Natl Acad Sci USA 101: 2476-2481, 2004.

BUB JD, MIYAZAKI T, IWAMOTO Y: Adiponectin as a growth inhibitor in prostate cancer cells. Biochem Biophys Res Commun 340: 1158-1166, 2006.

CALLE EE, THUN MJ: Obesity and cancer. Oncogene 23: 6365-6378, 2004. 
DAL MASO L, AUGUSTIN LS, KARALIS A, TALAMINI R, FRANCESCHI S, TRICHOPOULOS D, MANTZOROS CS, LA VECCHIA C: Circulating adiponectin and endometrial cancer risk. J Clin Endocrinol Metab 89: 1160-1163, 2004.

ENG J: http://www.rad.jhmi.edu/jeng/javarad/roc/JROCFITi.html 2006 November 7

FREEDLAND SJ, TERRIS MK, PRESTI JC, JR., AMLING CL, KANE CJ, TROCK B, ARONSON WJ: Obesity and biochemical outcome following radical prostatectomy for organ confined disease with negative surgical margins. J Urol 172: 520-524, 2004.

FREEDLAND SJ, SOKOLL LJ, MANGOLD LA, BRUZEK DJ, MOHR P, YIU SK, EPSTEIN JI, PARTIN AW: Serum leptin and pathological findings at the time of radical prostatectomy. J Urol 173: 773-776, 2005a.

FREEDLAND SJ, SOKOLL LJ, PLATZ EA, MANGOLD LA, BRUZEK DJ, MOHR P, YIU SK, PARTIN AW: Association between serum adiponectin, and pathological stage and grade in men undergoing radical prostatectomy. J Urol 174: 1266-1270, 2005 b.

GANN PH: Risk factors for prostate cancer. Rev Urol 4 (Suppl 5): S3-S10, 2002.

GIOVANNUCCI E, RIMM EB, STAMPFER MJ, COLDITZ GA, WILLETT WC: Height, body weight, and risk of prostate cancer. Cancer Epidemiol Biomarkers Prev 6: 557-563, 1997.

GOKTAS S, YILMAZ MI, CAGLAR K, SONMEZ A, KILIC S, BEDIR S: Prostate cancer and adiponectin. Urology 65: 1168-1172, 2005.

HOUSA D, HOUSOVA J, VERNEROVA Z, HALUZIK M: Adipocytokines and cancer. Physiol Res 55: 233-244, 2006.

HSING AW, REICHARDT JK, STANCZYK FZ: Hormones and prostate cancer: current perspectives and future directions. Prostate 52: 213-235, 2002.

ISHIKAWA M, KITAYAMA J, KAZAMA S, HIRAMATSU T, HATANO K, NAGAWA H: Plasma adiponectin and gastric cancer. Clin Cancer Res 11: 466-472, 2005.

KADOWAKI T, YAMAUCHI T: Adiponectin and adiponectin receptors. Endocr Rev 26: 439-451, 2005.

LE MARCHAND L, KOLONEL LN, WILKENS LR, MYERS BC, HIROHATA T: Animal fat consumption and prostate cancer: a prospective study in Hawaii. Epidemiology 5: 276-282, 1994.

MANTZOROS C, PETRIDOU E, DESSYPRIS N, CHAVELAS C, DALAMAGA M, ALEXE DM, PAPADIAMANTIS Y, MARKOPOULOS C, SPANOS E, CHROUSOS G, TRICHOPOULOS D: Adiponectin and breast cancer risk. J Clin Endocrinol Metab 89: 1102-1107, 2004.

MISTRY T, DIGBY JE, CHEN J, DESAI KM, RANDEVA HS: The regulation of adiponectin receptors in human prostate cancer cell lines. Biochem Biophys Res Commun 348: 832-838, 2006.

MIYAZAKI T, BUB JD, UZUKI M, IWAMOTO Y: Adiponectin activates c-Jun NH2-terminal kinase and inhibits signal transducer and activator of transcription 3. Biochem Biophys Res Commun 333: 79-87, 2005.

MIYOSHI Y, FUNAHASHI T, KIHARA S, TAGUCHI T, TAMAKI Y, MATSUZAWA Y, NOGUCHI S: Association of serum adiponectin levels with breast cancer risk. Clin Cancer Res 9: 5699-5704, 2003.

PETRIDOU E, MANTZOROS C, DESSYPRIS N, KOUKOULOMATIS P, ADDY C, VOULGARIS Z, CHROUSOS G, TRICHOPOULOS D: Plasma adiponectin concentrations in relation to endometrial cancer: a case-control study in Greece. J Clin Endocrinol Metab 88: 993-997, 2003.

SHIMIZU H, ROSS RK, BERNSTEIN L, YATANI R, HENDERSON BE, MACK TM: Cancers of the prostate and breast among Japanese and white immigrants in Los Angeles County. Br J Cancer 63: 963-966, 1991.

SOMASUNDAR P, FRANKENBERRY KA, SKINNER H, VEDULA G, MCFADDEN DW, RIGGS D, JACKSON B, VANGILDER R, HILEMAN SM, VONA-DAVIS LC: Prostate cancer cell proliferation is influenced by leptin. J Surg Res 118: 71-82, 2004.

TRUE LD: Surgical pathology examination of the prostate gland. Practice survey by American society of clinical pathologists. Am J Clin Pathol 102: 572-579, 1994.

WEI EK, GIOVANNUCCI E, FUCHS CS, WILLETT WC, MANTZOROS CS: Low plasma adiponectin levels and risk of colorectal cancer in men: a prospective study. J Natl Cancer Inst 97: 1688-1694, 2005. 